\title{
não deve dar a palavra aos amigos... assim não é justo! representações das crianças sobre o gestor da palavra na comunidade de investigação filosófica ${ }^{1}$
}

\author{
ana isabel santos ${ }^{2}$ \\ universidade dos açores/nica, - portugal \\ magda costa carvalho ${ }^{3}$ \\ universidade dos açores/nica - portugal
}

resumo

O presente artigo tem como objetivo a apresentação e discussão das representações das crianças acerca do papel do Gestor da Palavra (GP). Trata-se de um recurso concebido e desenvolvido no âmbito de sessões de Filosofia para Crianças, de acordo com a metodologia da comunidade de investigação filosófica (community of philosophical inquiry) de Matthew Lipman (2003) e de Ann Margaret Sharp (1987). Designamos como “Gestor da Palavra" o membro da comunidade de investigação responsável por escolher, durante o diálogo, quem fala e quando fala. Surge como uma estratégia para envolver ativamente as crianças nos procedimentos da sessão e a sua importância estende-se até às dimensões pedagógica e filosófica da comunidade de investigação. Adotou-se como metodologia o estudo de um caso exploratório, recorrendo-se a um questionário para realizar o levantamento das formas de pensar das crianças. Da análise de conteúdo do questionário, emergiram três subcategorias na definição daquilo que o GP deve e não deve fazer: cognitiva, ética e social. Destas, é a dimensão ética aquela que revela maior incidência de respostas, com implicações para dimensões fundamentais da Filosofia para Crianças como sejam a promoção do caring thinking (LIPMAN, 2003) e a conceção de autoridade na comunidade de investigação. Assim, o artigo divide-se em cinco secções: a Filosofia para Crianças como área científica e como programa curricular, com incidência no conceito de "comunidade de investigação filosófica"; o GP no âmbito da comunidade de investigação; a metodologia do estudo; a apresentação dos resultados e a sua discussão.

palavras-chave: filosofia para crianças; gestor da palavra; comunidade de investigação filosófica; poder; autonomia.

you should not give your friends the word ... that's not fair! representations of children on the word manager in the philosophical research community

abstract

The present article focuses on presenting and debating the representations of children on their role as Word-Managers (WM). This resource was created and developed in the scope of the Philosophy for Children sessions, according to the methodology of the community of

\footnotetext{
1 As autoras agradecem aos membros das comunidades de investigação filosófica com os quais trabalharam durante a recolha de dados para o presente artigo. Todos os dados recolhidos para esta investigação foram tratados de forma confidencial, para proteção da privacidade das crianças envolvidas. As autoras agradecem, ainda, ao Professor Eugenio Echeverría pelo incentivo dado a esta investigação e pela leitura atenta da primeira versão do manuscrito.

${ }^{2}$ E-mail: ana.is.santos@uac.pt

${ }^{3}$ E-mail: magda.ep.teixeira@uac.pt
} 
não deve dar a palavra aos amigos... assim não é justo! representações das crianças sobre o gestor da palavra na comunidade de investigação filosófica

philosophical inquiry of Matthew Lipman (2003) and Ann Margaret Sharp (1987). WordManager is the expression coined to refer to the member of the community of inquiry who is responsible for choosing, during the dialogue, who is going to speak and when. This strategy aims at actively involving the children in the session's procedure, and its importance locks with the pedagogic and philosophic dimensions of the community of inquiry. The methodology chosen was the study of an exploratory case, resorting to a query for each questionnaire in order to find out the children's ways of thinking. By analyzing the content of the questionnaire, in the definition of what the WM should and should not do, three subcategories came to light: cognitive, ethical and social. Of these, it is the ethical dimension that shows a larger number of responses, with implications towards the fundamental dimensions of Philosophy for Children, as the promotion of caring thinking (LIPMAN, 2003) and the concept of authority in the community of inquiry. Thus, the article is divided into five sections: Philosophy for Children as a scientific area and an educational program, focusing on the community of philosophical inquiry concept; the WM in the scope of the community of inquiry; the methodological casing of the research; presenting the results; and debating.

keywords: philosophy for children; word-manager, community of philosophical inquiry, power, autonomy.

no debe dar la palabra a los amigos... jasí no es justo! representaciones de los niños y niñas sobre el gestor de la palabra en la comunidad de investigación filosófica

resumen

El presente artículo tiene como objetivo la presentación y discusión de las representaciones de los niños y niñas sobre el papel del Gestor de la Palabra (GP). Se trata de un recurso concebido y desarrollado en el ámbito de las sesiones de Filosofía para Niños, de acuerdo con la metodología de la comunidad de investigación filosófica (community of philosophical inquiry) de Matthew Lipman (2003) y de Ann Margaret Sharp (1987). Designamos como "Gestor de la Palabra" al miembro de la comunidad de investigación responsable por escoger, durante el diálogo, quién habla y cuándo habla. Surge como una estrategia para envolver activamente a los niños y niñas en los procedimientos de la sesión y su importancia se extiende hasta las dimensiones pedagógica y filosófica de la comunidad de investigación. Se adoptó como metodología el estudio de un caso exploratorio, recorriendo a un cuestionario para realizar el levantamiento de las formas de pensar de los niños y niñas. Del análisis de contenido del cuestionario, emergieron tres sub-categorías en la definición de lo que el GP debe y no debe hacer: cognitiva, ética y social. De estas, es la dimensión ética aquella que revela mayor incidencia de respuestas, con implicaciones para dimensiones fundamentales de la Filosofía para Niños como son la promoción del caring thinking (LIPMAN, 2003) y la noción de autoridad en la comunidad de investigación. Así, el artículo se divide en cinco secciones: la Filosofía para Niños como área científica y como programa curricular, con incidencia en el concepto de "comunidad de investigación filosófica"; el GP en el ámbito de la comunidad de investigación; el enfoque metodológico del estudio; la presentación de los resultados y su discusión.

palabras-clave: filosofía para niños; gestor de palabra; comunidad de investigación filosófica; poder; autonomía. 
não deve dar a palavra aos amigos... assim não é justo! representações das crianças sobre o gestor da palavra na comunidade de investigação filosófica

\section{introdução}

A natureza democrática das comunidades de investigação revela-se nos temas e questões tratados durante o diálogo filosófico, bem como no modo como se operacionaliza o pensamento colaborativo e autorregulado característico da Filosofia para Crianças.

Neste contexto, surge o Gestor da Palavra (GP) como recurso filosóficopedagógico ao serviço das comunidades de investigação, que procura constituir-se enquanto estratégia para envolver ativamente as crianças nos procedimentos da sessão. Assim, o GP é o membro da comunidade de investigação responsável por escolher, durante o diálogo, quem fala e quando fala.

Esta investigação procura, por um lado, formalizar a existência do GP, quer em termos teóricos, quer em termos práticos, e, por outro lado, explorar as potencialidades deste recurso através das representações que dele fazem os membros da comunidade de investigação.

Metodologicamente optou-se pela realização de um estudo de caso exploratório, recorrendo-se a um questionário para realizar o levantamento das formas de pensar sobre o papel do GP. Estiveram envolvidas 36 crianças, de 8 e 9 anos, que constituem duas comunidades de investigação. O questionário foi analisado recorrendo-se à técnica de análise de conteúdo, que permitiu identificar três subcategorias na definição daquilo que o GP deve e não deve fazer.

\section{filosofia para crianças e comunidade de investigação filosófica}

A Filosofia para Crianças surgiu na década de 70 nos Estados Unidos da América como um programa curricular. Surgiu a partir dos trabalhos conjuntos de Matthew Lipman e de Ann Margaret Sharp, fundadores do Institute for the 
não deve dar a palavra aos amigos... assim não é justo! representações das crianças sobre o gestor da palavra na comunidade de investigação filosófica

Advancement of Philosophy for Children, na Montclair State University (New Jersey).

O programa teve o seu início com um projeto liderado por Lipman, na altura professor de Lógica na Universidade de Columbia, que procurava ajudar as crianças a lidarem com algumas ambiguidades da linguagem (LIPMAN; MORIYÓN, 2011, p. 186). O autor considerava que as competências promovidas pelo pensamento filosófico permitiam detetar falácias e equívocos em discursos marcados por ambiguidades linguísticas intencionais, como são a publicidade e a propaganda política. Lipman defendia que as competências para detetar essas ambiguidades deveriam ser cultivadas desde a infância já que, evitando que as crianças fossem induzidas em erro, torná-las-ia mais conscientes, problematizadoras e ativas na realidade circundante.

Nesse contexto, escreveu Harry Stottlemeier's Discovery, a primeira história para crianças que haveria de inaugurar, poucos anos mais tarde e já em colaboração com A. M. Sharp, um currículo escolar completo. Lipman e Sharp conceberam durante as décadas seguintes um programa com 11 histórias para crianças, dirigido a diferentes faixas etárias, e respetivos manuais orientadores para os professores.

O objetivo primordial deste currículo prendia-se com a reconstrução de alguns dos mais eminentes conceitos e perspetivas da tradição filosófica ocidental num formato que pudesse ser assumido pelas crianças, não num sentido de aquisição passiva, mas de apropriação autónoma e autorregulada (REED; SHARP, 1998, p. 9). O modelo pedagógico concebido para cumprir este desiderato no interior das salas de aula assumiu a designação de "comunidade de investigação filosófica" (community of inquiry), numa herança do pragmatismo americano claramente assumida pelos autores (LIPMAN, 2003, p. 20).

De John Dewey, Lipman recebeu a conceção da educação como um processo de investigação, contrariando as perspetivas clássicas que se centravam apenas na aquisição do conhecimento como produto fechado (LIPMAN, 2003, p. 20). De Charles 
Peirce, adotou a expressão "comunidade de investigação", referindo-se a um conjunto de pessoas que desenvolvem uma prática de pensamento comum em torno dos mesmos procedimentos e objetivos (LIPMAN, 2003, p. 20). Concebida por Peirce para se referir à investigação de caráter científico, a noção de comunidade de investigação afirmou-se na Filosofia para Crianças como a infraestrutura (LIPMAN, 2008) mais adequada à prática intersubjetiva de um diálogo colaborativo e autorregulador, que visa a construção de perspetivas próprias sobre os problemas em análise.

Através da promoção do diálogo filosófico em comunidade de investigação, a Filosofia para Crianças assumiu ainda como objetivo o desenvolvimento de competências de pensamento, designadas por Lipman como pensamento multidimensional (LIPMAN, 2003, p. 199). Situando-se em oposição à divisão de inspiração cartesiana entre corpo e mente, procurava-se promover no exercício do pensamento um equilíbrio entre a dimensão cognitiva e a dimensão afetiva, entre o perceptual e o conceptual, entre o físico e o mental. Assim, e tal como afirma o autor, apesar de ter a aparência de uma comum discussão em sala de aula, a intencionalidade das sessões em comunidade de investigação confere ao diálogo entre as crianças a profundidade do pensamento filosófico, competindo ao facilitador (adulto) a introdução de critérios éticos, estéticos, políticos ou metafísicos na consideração das questões. Sendo um diálogo que visa construir conhecimento, e não apenas transmiti-lo, o facilitador modela o modo de pensamento filosófico que o grupo, como um todo, deve aprender a produzir.

A comunidade de investigação tece-se das relações entre as pessoas, "falantes e ouvintes que comunicam uns com os outros de forma imparcial e consistente, que se dispõem a reconstruir as ideias dos outros e a submeter as suas próprias posições ao processo autorregulador da investigação filosófica" (SHARP, 1987, p. 42). Em suma, o diálogo em comunidade, sobre temas e questões de interesse das crianças e facilitado por um membro com formação e treino filosóficos, permite então recorrer e até 
não deve dar a palavra aos amigos... assim não é justo! representações das crianças sobre o gestor da palavra na comunidade de investigação filosófica

reconstruir alguns dos principais conceitos da tradição filosófica (KENNEDY, 2004, p. $744)^{4}$. E estes conceitos, por sua vez, enriquecem a experiência das crianças por permitirem descobrir, nas mais comuns experiências quotidianas, a profundidade de sentido caracterizadora da realidade plenamente humana.

A comunidade de investigação caracteriza-se pela complexidade inerente à sua estrutura, cuja construção decorre de uma prática continuada de pensamento em conjunto. Tratando-se de um trabalho colaborativo, o sentido de comunidade surge quando o sujeito de pensamento emerge como um "nós" coletivo construído pelos seus membros (SHARP, 1987, p. 43). É esta complexidade que justifica que à pergunta "o que é uma comunidade de investigação?" se acrescente uma outra "quando há uma comunidade de investigação?". (COSTA-CARVALHO; MENDONÇA, 2016).

\section{o gestor da palavra como recurso da comunidade de investigação filosófica génese de um recurso}

"Gestor da Palavra" (GP) é a designação dada ao membro da comunidade de investigação responsável por decidir, em cada sessão, quem intervém no diálogo do grupo e quando o deve fazer. Sendo em regra uma das funções inerentes à tarefa do facilitador, a decisão de a desvincular das competências de facilitação revela-se, desde o primeiro momento, repleta de relevância e potencialidade do ponto de vista de consolidação pedagógica e filosófica da própria comunidade. Em cada sessão, a gestão das intervenções é atribuída a um membro diferente da comunidade, concedendo-se a todos a possibilidade de protagonizarem a tarefa. Tal como nos relembram Splitter e Sharp (1995, p. 145), “Vale a pena enfatizar que um diálogo

\footnotetext{
4 A eficácia da comunidade de investigação como instrumento ou metodologia pedagógica foi inegável, ao ponto de se ter autonomizado em relação programa original de Filosofia para Crianças. Relembre-se que atualmente o maior organismo internacional nesta área, que congrega especialistas de todo o mundo, tem como designação The International Council of Philosophical Inquiry with Children (ICPIC). Para além disso, outras áreas assumiram os mesmos pressupostos pedagógicos e propuseram comunidades de investigação de diferentes naturezas, como comunidade de investigação matemática, comunidade de investigação científica ou comunidade de investigação histórica.
} 
maduro (que represente uma comunidade de investigação madura) é mais conduzido pelos alunos do que pelo professor." 5

Este foi um recurso que observamos pela primeira vez em janeiro de 2012, numa sessão de Filosofia para Crianças a que assistimos na Escola Pequeño Sol, em San Cristóbal de las Casas, Chiapas, México. A facilitadora, uma professora do grupo orientado por Eugenio Echeverría, conduzia o diálogo em termos filosóficos, mas era uma das crianças que, em cada sessão, se responsabilizava por atribuir aos colegas a vez de participar.

De regresso a Portugal, nomeamos a estratégia como "Gestão da Palavra" e adotámo-la nas nossas sessões de Filosofia para Crianças, tendo imediatamente recebido uma excelente reação por parte das crianças. Conceder-lhes a oportunidade de exercerem uma tarefa tradicionalmente reservada ao adulto permitiu-lhes uma maior apropriação da sessão como um processo que eles ajudam a construir e não apenas como um produto que recebem (já feito) do facilitador.

Simultaneamente, o GP introduz nos grupos uma outra forma de participação, já que algumas das crianças que têm dificuldade em intervir verbalmente no diálogo ganham maior à-vontade com a prática da comunidade ao desempenharem este papel. Longe de uma manobra condescendente por parte do facilitador, a introdução do GP confirma às crianças que as opções que elas tomam na comunidade são fundamentais para a comunidade como um todo.

Reconhecer e praticar o direito das crianças à participação ativa enquanto plenos membros das suas comunidades implica, como muito bem refere J. Haynes, alterações profundas no modo como concebemos a infância, bem como na forma como perspetivamos as relações de conhecimento e de poder dentro das salas de aula (HAYNES, 2008, pp. 19-21). Consideramos que o GP encerra virtualidades a esses dois níveis - pedagógico e filosófico - e que, como tal, se justifica o aprofundamento de ambos. Contudo, sublinha-se que esta dupla dimensão do GP não se traduz numa

\footnotetext{
5 "It is worth emphasizing that a mature dialogue (representing a mature community of inquiry) is student driven, rather than teacher driven."
} 
não deve dar a palavra aos amigos... assim não é justo! representações das crianças sobre o gestor da palavra na comunidade de investigação filosófica

dicotomização do recurso: sem a dimensão filosófica, faltar-lhe-ia o enquadramento conceptual de referência, sem a dimensão pedagógica faltar-lhe-iam as estratégias para a sua operacionalização.

\section{dimensão pedagógica do gestor da palavra}

Em termos pedagógicos, a gestão da palavra pode ser entendida como uma "competência processual" (procedural competence), no sentido em que promove a autoconstrução consciente de relações entre os membros da comunidade de investigação (SPLITTER; SHARP, 1995, pp. 109-110). Mais especificamente, o recurso ao GP permite que as crianças compreendam o alcance da ligação entre as partes e o todo, isto é, os membros individuais e a comunidade, ao perspetivarem-se como indivíduos ao serviço do grupo.

O GP torna-se, então, corresponsável por aquilo que se passa na comunidade, exercendo pelo grupo a tarefa de coordenação dos contributos de cada membro para o espaço público da comunidade. Assim, adquirir esta competência processual implica aprender a administrar três níveis de interesses: ao gerir a palavra, a criança vê-se confrontada com a necessidade de articular de forma eficaz o seu interesse próprio no diálogo (quando, como membro da comunidade, quer intervir); os interesses dos outros membros (que se encontram com o dedo no ar); e o interesse da própria comunidade de investigação enquanto tal (qual a melhor decisão para a investigação em curso).

Ainda de acordo com Splitter e Sharp, as competências processuais são de natureza transversal. A Filosofia para Crianças apresenta-se como o solo propício ao seu cultivo porque, enquanto programa de metacognição, permite que as crianças confrontem e examinem os próprios procedimentos promotores do diálogo. Neste contexto, o GP dá às crianças um relance sobre algumas das estruturas de decisão que suportam a dinâmica do grupo. Quando tem de escolher quem falará de seguida, o 
GP encontra-se nos bastidores da prática do diálogo em comunidade e, naturalmente, experiencia as mais-valias, bem como as dificuldades, inerentes à função.

Julgamos que a este tipo de recursos se referia G. Burgh quando chamava a atenção para a dimensão prática do papel de facilitação numa comunidade de investigação filosófica, isto é, para a necessidade de introduzir aprendizagens práticas relacionadas com os próprios processos sociais envolvidos no diálogo (BURGH; YORSHANSKY, 2011, p. 442). O exercício do GP configura-se-nos como um instrumento eficaz na produção desse tipo de aprendizagens.

Para além da processualidade e da transversalidade, a relevância pedagógica do GP faz-se também notar nos momentos de avaliação das sessões de Filosofia para Crianças. A partir do momento em que se introduz o GP como recurso, a comunidade assume-o como mais um dos itens de consideração quando se ocupa de ponderar o que correu bem e o que correu mal na sessão. Nos momentos de avaliação, as comunidades sentem necessidade de, naturalmente, indicarem ao colega que desempenhou a função de GP aquilo que correu menos bem nesse exercício. Esta avaliação permite-lhes apurar gradualmente o recurso, tomando consciência da sua utilização menos adequada, bem como dos benefícios que pode trazer para o grupo quando exercida de modo ajustado. Aprimora-se ainda mais a consciência avaliativa da comunidade, com claras repercussões para a sua autorregulação enquanto grupo.

Assim, ainda que os primeiros tempos de vida de uma comunidade de investigação filosófica exijam uma presença mais forte por parte do facilitador (SPLITTER; SHARP, 1995, pp. 148-149), à medida que a comunidade ganha maior à vontade com determinadas funções, como seja o GP, compreende a relevância de as decisões não se encontrarem apenas concentradas nas mãos do adulto e adquire a habilidade de as exercer. Foi por terem esta consciência que, numa das sessões em comunidade de investigação, à pergunta "O que deve fazer o GP?", ouvimos uma resposta que parece dar conta desta necessária familiaridade com o recurso: “O GP 
não deve dar a palavra aos amigos... assim não é justo! representações das crianças sobre o gestor da palavra na comunidade de investigação filosófica

deve ter experiência" (2-E). E a experiência só se ganha... no próprio exercício das tarefas.

\section{dimensão filosófica do gestor da palavra}

A introdução do GP como recurso nas sessões em comunidade de investigação não se faz sem compromissos filosóficos de fundo. Para além da dimensão pedagógica do recurso, a que já aludimos, existem dois grandes eixos filosóficos que o mesmo convoca: uma (efetiva) participação democrática e um exercício (justo) do poder. Detenhamo-nos um pouco sobre ambos.

O programa de Filosofia para Crianças aspira à transformação das salas de aula em comunidades de investigação filosófica (SPLITTER; SHARP, 1995, p. 140; LIPMAN, 2003, p. 20). Em termos epistemológicos, esta aspiração funda-se numa conceção construtivista, social e falibilista do conhecimento (DANIEL, 2007). Mas o projeto de Filosofia para Crianças conjuga estes pressupostos epistemológicos com fundamentos de natureza política, uma vez que, sendo o conhecimento construído na interação gerada entre os membros da comunidade de investigação, esta assume-se como um espaço público de participação e de corresponsabilização.

A comunidade de investigação é um microcosmos da democracia, quer pela sua natureza autónoma (selfgoverning) e autorregulada (LIPMAN, 1998), quer pelo compromisso do diálogo racional para com valores como o pluralismo e a liberdade (SHARP, 1991). O propósito não é criar um laboratório que reproduza a sociedade democrática real numa pequena escala ficcionada e artificial, mas antes que a comunidade de investigação filosófica seja, ela própria, vivência política da democracia. No dizer de Ann Sharp, trata-se de uma experiência real (a lived experience), (SHARP, 1987, 38). O GP insere-se neste contexto, ao afirmar-se como um recurso que promove na comunidade de investigação uma educação politicamente consciente e participativa (ECHEVERRIA; HANNAM, 2017).

De acordo com o modelo de Lipman e Sharp, as comunidades de investigação escolhem como espaço pedagógico privilegiado a disposição de todos os membros, 
incluindo o facilitador, em círculo e ao mesmo nível. Desta forma, assumem todos a posição filosófica de co-construtores de um espaço comum de conhecimento. $\mathrm{O}$ espaço físico, cognitivo e afetivo que medeia entre os participantes afirma-se como o centro onde a intersubjetividade se torna prática filosófica. A forma como cada um intervém deve, assim, respeitar e promover a comunidade enquanto locus político e social. Aprende-se como um grupo, e não apenas num grupo (BENJAMIN; ECHEVERRIA, 1992).

Entender política e socialmente a comunidade de investigação filosófica implica uma participação democrática de facto, isto é, o facilitador não deve reduzir o contributo das crianças a consultas periódicas de opiniões e vontades. Em termos pedagógicos, torna-se necessário envolvê-las ativamente nos processos contínuos de tomada de decisão que estruturam a própria comunidade de investigação, permitindo-lhes tomar a iniciativa e assumir a responsabilidade do que se passa na sessão.

É neste contexto que se pode enquadrar o conceito de J. Haynes de uma "autonomia comunicativa", enquanto conjunto de distintas formas de comunicação que maximizam a autonomia das crianças, seja nos momentos formais do diálogo filosófico, seja nos momentos informais de suporte a esse diálogo (HAYNES, 2008, pp. 19-21). O recurso ao GP insere-se indubitavelmente no conjunto de atividades que potenciam a autonomia comunicativa, não apenas centrada nas intervenções de cada um, mas promotora da rede intersubjetiva que permite fazer brotar o pensamento próprio do grupo.

São, de novo, visíveis as relações entre a dimensão epistemológica e a dimensão política da comunidade de investigação filosófica: "Ignorar que um compromisso para com a comunidade de investigação é também um compromisso político é ignorar a relação pensamento e ação."6 (BURGH; YORSHANSKY, 2011, p. 440). Para que a comunidade seja capaz de construir um entendimento

\footnotetext{
${ }^{6}$ "To ignore that a commitment to the community of inquiry is also a political commitment is to ignore the relationship between thought and action."
} 
não deve dar a palavra aos amigos... assim não é justo! representações das crianças sobre o gestor da palavra na comunidade de investigação filosófica

epistemológico, é necessário que deixe de ser uma coleção de eus e assuma um contínuo nós (SHARP, 1987, p. 43). E a promoção deste sujeito coletivo auto-consciente faz-se através de recursos que, como o GP, permitam aos membros (partes) a experiência da comunidade (todo).

Em consequência desta opção por uma democraticidade real e maximamente participada, e tal como acontece com todos os espaços públicos, na comunidade de investigação filosófica a rede relacional impõe a necessidade de se ter em conta o modo como o poder é exercido e, sobretudo, como se distribui pelos seus vários membros. $\mathrm{O}$ verdadeiro significado de capacitar as crianças implica delegar cuidada e, sobretudo, criteriosamente as funções dentro da sala de aula: "empowering significa desenvolver nas pessoas competências que lhes possibilitem agir de modo seguro e por si próprias (i.e. autonomamente), e para isto são necessárias intervenções positivas e direcionadas"7 (SPROD, 2001, p. 68).

A isto designamos como intencionalidade no uso do poder. Esta intencionalidade deve pressupor, por parte do adulto, a natureza da dimensão provisória presente no exercício de algumas das funções do facilitador, como seja o de GP. Paralelamente, a intencionalidade no uso do poder numa comunidade de investigação filosófica deve promover oportunidades para que as crianças, elas próprias, adquiram as competências necessárias ao exercício desse poder. Numa sessão de Filosofia para Crianças, o facilitador sabe que exerce algumas tarefas em nome das crianças, mas apenas enquanto elas não se encontram aptas para o fazer em nome próprio. Mas também sabe que, se não proporcionar momentos na sessão para que elas aprendam a complexidade presente no exercício desses poderes, experienciando-a, nunca as crianças estarão preparadas para os assumir. Exercer a gestão da palavra configurase, então, como uma aprendizagem das responsabilidades implicadas nas tomadas de decisão no que respeita à promoção do funcionamento do grupo, melhorando as habilidades de autorregulação da comunidade enquanto todo.

\footnotetext{
7 "empowering means developing in people the capacities to be able to act powerfully on their own (i.e. autonomously), and this require positive and purposeful interventions."
} 
Entregar a função de GP às crianças é uma forma de exercício mais justo e equitativo do poder dentro da sala de aula. O GP pode, então, enquadrar-se no contexto de um conceito positivo de poder, de uma "rede produtiva que atravessa o todo social, uma força capaz de criar formas de conhecimento e de discurso" (FOUCAULT, 1991, p. 61) dentro da comunidade. Conforme veremos na apresentação dos dados recolhidos junto das crianças, o GP não é representado como uma força autoritária e repressiva que impõe o seu jugo sobre os outros, mas antes como uma forma (positiva) de gerir o espaço público da comunidade. Ao GP conferese uma responsabilidade para com a gestão do grupo no seu todo: por um lado, porque deve atender aos pedidos para intervir de todos os membros e, por outro, porque deve cuidar da distribuição justa da palavra (escolher diferentes membros para participar, evitar critérios parciais de escolha como o género ou a amizade, etc.).

\section{metodologia}

O presente trabalho de investigação reveste-se de um caráter exploratório, atendendo, por um lado, à dimensão científica que se prende com a ausência de investigação sobre o objeto de estudo, nomeadamente o GP enquanto estratégia filosófica e pedagógica que permite reforçar a construção da identidade do grupo como um todo. Por outro lado, esta necessidade emergiu, numa dimensão mais prática, dos processos de avaliação encetados em cada uma das sessões de Filosofia para Crianças, durante os quais se começou a registar uma sistemática perceção negativa do papel do GP por parte das crianças que, nem sempre, parecia corresponder à realidade dessas mesmas sessões, pelo menos na perspetiva da facilitadora.

Assim, e no intuito de aprofundar esta questão, foram encetados procedimentos metodológicos diversificados que permitissem, futuramente, uma triangulação de fontes diversas de recolha de informação. 
não deve dar a palavra aos amigos... assim não é justo! representações das crianças sobre o gestor da palavra na comunidade de investigação filosófica

Neste sentido, o estudo procurou, em primeiro lugar, realizar uma observação mais sistematizada da interação do GP com o resto da comunidade de investigação filosófica, que se concretizou na construção de sociogramas. Através deles procurouse perceber a quem é que o GP privilegiava no momento de escolha de colegas para participarem na discussão que estava a ter lugar na comunidade. A análise dos sociogramas, pela riqueza de conteúdo, será objeto de análise e discussão num próximo artigo.

Paralelamente, foram realizados inquéritos de questões abertas, que procuraram fazer um levantamento das representações do grupo de crianças sobre o papel do GP. Este questionário apenas solicitava aos alunos a identificação daquilo que o GP deve e não deve fazer e foi realizado numa das sessões de Filosofia para Crianças, tendo sido utilizado como estímulo para o diálogo. A informação contida nos questionários foi analisada através de análise de conteúdo temática (BARDIN, 1995), seguindo uma forte lógica indutiva, com grande recetividade às informações empíricas recolhidas. O presente estudo tem em conta os dados recolhidos através deste instrumento.

Um terceiro elemento introduzido foi um novo item na grelha de observação da comunidade de investigação, designado por "Nesta sessão, a gestão da palavra foi...". Pretendeu-se que os observadores ${ }^{8}$ avaliassem intencionalmente o desempenho do GP no decorrer da sessão.

Participaram no estudo um total de 36 crianças, com idades compreendidas entre os 8 e os 9 anos, sendo 21 raparigas e 15 rapazes, que frequentavam duas turmas do $3^{\circ}$ ano do ensino básico (19 crianças da turma A e 17 da turma B). Ambas

\footnotetext{
8 No contexto do trabalho desenvolvido por Michel Sasseville e Michel Gagnon (2007), adota-se nas sessões em comunidade de investigação o recurso a "observadores", isto é, em cada sessão são designados dois membros que ficam fora do círculo da comunidade de investigação e a quem são atribuídas grelhas de observação de algumas das competências filosóficas usadas durante a sessão. No final, os observadores relatam ao restante grupo as suas apreciações sobre o modo (processual e substantivo) como decorreu a sessão, sendo este o momento fundamental para a autorregulação do trabalho do grupo.
} 
as turmas estavam familiarizadas com a metodologia da Filosofia para Crianças desde o $1^{\circ}$ ano.

\section{apresentação dos resultados}

Dado o grande enfoque colocado pelas crianças sobre a prestação do GP quando avaliaram as primeiras sessões em que se usou o recurso, considerou-se pertinente proporcionar à comunidade de investigação um espaço de discussão sobre ele. Nesta discussão surgiu a necessidade de se aprofundar a representação que a comunidade fazia do GP, pelo que se optou, para além do diálogo, por colmatar a oralidade com um registo escrito, através do qual cada criança pudesse refletir sobre “O que o GP deve fazer" e "O que o GP não deve fazer". A atividade definia a priori estas duas categorias principais de análise, sendo que a posterior análise de conteúdo aos registos escritos permitiu identificar três subcategorias: dimensão cognitiva; dimensão ética; dimensão social.

\section{a dimensão cognitiva do papel do gp}

A dimensão cognitiva engloba os registos que se referem à atenção ou desatenção do GP em relação ao que se passa à sua volta. Das três dimensões identificadas, esta é aquela que apresenta menor número de indicadores: 4 para a categoria "O que deve fazer" e 3 para a categoria "O que não deve fazer".

No que respeita à categoria "O que deve fazer o $\mathrm{GP}^{\prime}$, a dimensão cognitiva prende-se com competências de observação e de atenção às solicitações de intervenção dos membros da comunidade. Nesta dimensão, surgem indicadores de duas naturezas diferentes: por um lado, registar quem pretende intervir e, por outro lado, servir como regulador dos comportamentos do grupo. Da totalidade de indicadores para esta dimensão, é a primeira que reúne maior número de unidades de registo, sendo que "Estar atento" registou 7 unidades de registo, como por exemplo: "deve estar atento" (1D; 1C; 1M; 1N) ou "Deve ter atenção" (1I); "Estar atento a quem põe o 
não deve dar a palavra aos amigos... assim não é justo! representações das crianças sobre o gestor da palavra na comunidade de investigação filosófica

dedo no ar" registou 11 unidades, referindo, por exemplo: "dar a palavra às pessoas que põem o dedo no ar" (1F) ou "virar a cabeça para o lado para ver toda a gente, para ninguém dizer que o gestor da palavra não o escolheu porque não o viu" (1F); e "Olhar para todos os lados" (1E), 1 unidade de registo. O papel do GP enquanto regulador comportamental apenas foi identificado numa resposta, onde se lê: "ver se elas [pessoas] estão a portar-se bem" (1A).

No que respeita à categoria "O que não deve fazer o GP", a dimensão cognitiva apresenta igualmente respostas diversificadas. Por um lado, indicadores como "esquecer-se da comunidade" e "esquecer-se de quem está ao seu lado" remetem para a necessidade de ter consciência das necessidades de participação do outro no diálogo, como ficou registado no exemplo: "se alguém estiver ao lado do gestor e o gestor não der a palavra" (2E); por outro lado, "estar distraído" aponta para a necessidade de o próprio GP autorregular o seu comportamento, como assinalam os casos 2A "não conversar com ninguém" e 2M "não deve estar com a cabeça na lua".

\section{a dimensão ética do papel do gp}

A dimensão ética remete para indicadores que se prendem com a natureza das escolhas feitas pelo GP que, no geral, são entendidas como criteriosas ou, pelo contrário, como irrefletidas. Esta é a dimensão que apresenta maior número de indicadores, quer na categoria "O que deve fazer" (com 12 indicadores), quer na categoria "O que não deve fazer" (com 10 indicadores), bem como maior complexidade no conteúdo das respostas.

Relativamente à categoria "O que deve fazer", identificam-se três níveis diferentes de pensar o papel do GP. O primeiro nível refere-se à natureza própria do recurso e pode ser observado nos seguintes indicadores: "dar a palavra" (2 unidades de registo); "dar a palavra aos outros" (5 unidades de registo); "dar a palavra a si próprio" (1 unidade de registo) e "dar a palavra a quem tem o dedo no ar" (3 unidades de registo). São alguns exemplos deste tipo de respostas os seguintes: "deve 
dar a palavra a todas as pessoas que estão com o dedo no ar e também a si próprio" (2B); "escolher as pessoas que ainda não falaram" (1B).

Se este primeiro nível se reporta ao que deve fazer o GP, já o segundo nível centra-se em como deve o GP cumprir as funções que lhe são naturalmente adstritas. Isto é, nos indicadores recolhidos torna-se clara a identificação de critérios que permitem fundamentar a escolha de quem deve intervir no diálogo, tais como "escolher quem não falou" (3 unidades de registo); "escolher quem falou pouco" (1 unidade de registo); "escolher quem está há mais tempo com o dedo no ar" (1 unidade de registo); "escolher várias pessoas" (5 unidades de registo); "dar a palavra a todos" (10 unidades de registo); "dar a palavra a todos pelo menos uma vez" (1 unidade de registo) e "escolher as pessoas de uma forma equilibrada" (1 unidade de registo). Neste nível encontramos as seguintes repostas: "o gestor da palavra deve dar às pessoas que ainda não conseguiram falar" $(2 \mathrm{~N})$; "deve dar a palavra a várias pessoas" (2F); "variar nas pessoas que escolhe" $(1 \mathrm{~N})$; “deve ter a responsabilidade de tentar não dar a palavra sempre aos mesmos" (2M).

O terceiro nível respeita a mesma dinâmica de complexificação verificada do primeiro para o segundo e reporta-se ao porque deve o GP escolher determinados membros da comunidade em detrimento de outros. Apesar de se identificar apenas numa unidade de registo, este indicador encontra-se formulado com grande clareza: “O GP deve dar a palavra às pessoas todas, assim é justo!" (2I).

Também na categoria “O que não deve fazer o GP”, é possível identificar os mesmos três níveis de análise. Contudo, contrariamente ao que se verifica na categoria "O que deve fazer o GP", neste caso no primeiro nível (a natureza própria do GP enquanto recurso da comunidade, isto é, o que não deve fazer) apenas se encontrou o indicador "Não dar a palavra" com uma unidade de registo.

Em relação ao segundo nível, referente a como não deve o GP exercer as suas competências, é onde se regista maior número de indicadores e de unidades de registo. Assim, encontramos "Escolher as mesmas pessoas" (18 unidades de registo), 
não deve dar a palavra aos amigos... assim não é justo! representações das crianças sobre o gestor da palavra na comunidade de investigação filosófica

"Dar a palavra sempre a si" (4 unidades de registo), "Escolher os amigos ou amigas" (4 unidades de registo), “Escolher quem já falou (muito) quando há outras pessoas que querem falar" ( 3 unidades de registo), "Escolher só metade da comunidade" (2 unidades de registo), "Dar a palavra ao seu melhor amigo" (2 unidades de registo), "Escolher quem já falou mais de duas vezes" e "Escolher só as raparigas ou só os rapazes" (ambas com 1 unidade de registo). Alguns exemplos deste tipo de respostas são os seguintes: "Não deve dar a palavra às pessoas que já falaram muito, sabendo que há outras que ainda não falaram muito ou não disseram a coisa que era para dizer" (1O); "o gestor da palavra não deve dar a palavra mais de uma vez quando alguém ainda não falou e está há muito com o dedo no ar" (2J).

No terceiro nível de análise (porque não deve o GP escolher determinados membros da comunidade), foram identificados três indicadores que representam um número igual de critérios justificativos de uma má opção: o egoísmo, a desigualdade e a injustiça. Estes indicadores foram observados nos exemplos: "não dar a palavra sempre a si" (1E); "ser egoísta e escolher sempre a si mesmo" (1F); "o gestor da palavra não deve dar a palavra aos amigos preferidos, assim não é justo!" (2I); "não deve julgar as pessoas (primeiro as favoritas)" (2K); “escolher sempre as raparigas ou os rapazes" (1F).

\section{a dimensão social do papel do gp}

A dimensão social contempla questões relacionadas com as atitudes promotoras, ou desfavoráveis, do GP relativamente à comunidade de investigação filosófica. Na categoria "O que deve fazer", foram encontrados dois indicadores: "Ter experiência" (1 unidade de registo - 2E) e "Participar na comunidade" (2 unidades de registo). É de notar que, nestes casos, foram identificadas algumas das principais competências do diálogo filosófico, como sejam "discordar e concordar, dar razões e dar exemplos" (2O) ou "também tem de falar" (1C). 
Já na categoria "O que não deve fazer", verifica-se um maior número de indicadores (6): "Portar-se mal" (2 unidades de registo - 2A e 2O) e "Sair para ir à casa de banho" (1G), "Falar alto" (1A), "Dançar, cantar e dormir" (1A), “Falar fora da vez" (2B), "Demorar tempo a escolher as pessoas" (2K), todos com 1 unidade de registo.

\section{discussão dos resultados e conclusão}

A primeira constatação que surge na leitura dos resultados prende-se com a prevalência de respostas referentes à dimensão ética, em detrimento das dimensões cognitiva e social do papel do GP. Este facto pode ser um indicador de que, para as crianças, o que está em causa ao exercerem esta função é, sobretudo, uma questão de escolha. E que essa escolha, para promover o diálogo da comunidade, deve ser intencional e criteriosa. Em síntese, encontram-se 4 grandes critérios de definição das boas escolhas do GP: (a) deve promover a igualdade no acesso à palavra entre todos os membros da comunidade, evitando o egoísmo, bem como diferenciações motivadas por questões de amizade ou de género; (b) deve fomentar o equilíbrio na forma como decide quem fala, não deixando que determinados elementos monopolizem o diálogo; (c) deve respeitar a ordem pela qual a palavra é pedida e, por último, (d) deve ter em atenção uma gestão justa do espaço de intervenção. De notar que, apesar de o segundo e de o terceiro critérios indicados poderem entrar em conflito entre si, não houve nenhum registo neste sentido, provavelmente pelo tempo utilizado no procedimento de recolha das respostas que inviabilizou uma discussão e aprofundamento posteriores.

Estes resultados levam-nos a concluir que, de facto, o GP pode revelar-se uma estratégia promotora de consciencialização ética das escolhas em relação ao outro: seja ele um elemento individual da comunidade, seja a própria comunidade no seu todo ou até o diálogo filosófico construído em grupo no decorrer da sessão. De sublinhar que, numa sessão posterior, já depois de recolhidos os dados, uma das crianças 
não deve dar a palavra aos amigos... assim não é justo! representações das crianças sobre o gestor da palavra na comunidade de investigação filosófica

referiu que era necessário introduzir uma nova regra para o bom uso do papel do GP: no decorrer da sessão, se dois elementos da comunidade estiverem a dialogar sobre uma determinada questão, o GP deve respeitar essa dinâmica dialógica e, para salvaguardar a integridade do pensamento produzido, não deve passar a palavra a um terceiro elemento. Considera-se este um indicador da presença do caring thinking enquanto um dos aspetos da abordagem multidimensional do pensamento advogada por M. Lipman (2003), no sentido em que revela preocupação pela substância do diálogo propriamente dito enquanto foco de importância para a comunidade de investigação (SHARP, 2007).

No entanto, é interessante que nas representações das crianças não surjam apenas indicadores éticos, uma vez que, parecendo que o GP apenas tem por função a escolha de quem fala, na verdade há predisposições cognitivas e sociais igualmente relevantes de que as crianças têm noção.

Quanto à dimensão cognitiva, a atenção é fundamentalmente o indicador que se destaca como condição de possibilidade de uma boa gestão da palavra. Neste âmbito, algumas respostas parecem indiciar que as crianças representam o GP como uma extensão do papel do adulto na sessão, quer pela regulamentação dos comportamentos do grupo, quer pela necessidade de atender ao grupo enquanto comunidade (e não apenas uma coleção de indivíduos). Esta conclusão apoia-se quer na categoria "O que deve fazer o GP", pelo facto de haver uma resposta com o indicador "estar atento ao comportamento do grupo" (1A), quer na categoria "O que não deve fazer o GP", pela resposta: "esquecer-se da comunidade" (1C). No entanto, e como veremos, esta delegação de poderes não é entendida como um fator promotor de um estatuto diferenciado do GP enquanto membro da comunidade.

No que respeita à dimensão social, estão em causa comportamentos gerais que, por um lado, promovam o trabalho filosófico da comunidade e, por outro, não sejam disruptivos do ambiente pedagógico da sessão. No primeiro caso, por exemplo, uma criança referiu que o GP deve "discordar, concordar, dar razões e dar exemplos", 
numa lógica de utilização das regulares competências da comunidade de investigação filosófica. No segundo caso, são referidos comportamentos e atitudes reveladoras de um funcionamento normal do espaço de aula. Estes indicadores vêm, então, reforçar que, apesar de ser um elemento responsável pelo funcionamento do diálogo, as crianças veem o GP também como um membro da comunidade, em condição de igualdade com os outros colegas e não como uma autoridade exterior. Esta constatação intensifica-se se tivermos em conta que, no momento de avaliação conjunta da sessão, a prestação do GP é um elemento naturalmente recorrente na autorregulação crítica da comunidade. Podemos, assim, afirmar que o GP enquanto recurso pedagógico-filosófico no âmbito da Filosofia para Crianças promove a ideia de que o poder regulador não está confinado a um elemento do grupo, mas é pertença da própria comunidade.

Para terminar, é importante reconhecer que, apesar de se terem encontrado resultados de grande riqueza, esta investigação carece de ser aprofundada e complementada com a informação recolhida através dos sociogramas e da avaliação realizada pelas crianças, nas grelhas de observação das sessões, acerca do papel do GP, e anteriormente referidas.

Para além destes aspetos, ficam por estudar igualmente as representações das professoras regulares das duas turmas, a transposição do recurso para o contexto de sala de aula, bem como a evolução das representações das crianças sobre o papel do GP. Porque, como referiu uma das professoras num questionário de balanço do ano letivo: "os alunos já perceberam que há uma relação [entre a Filosofia para Crianças e aquilo que se passa na sala de aula] e verbalizam-no."

Retomando a identificação do GP com uma competência processual, é necessário reforçar que os frutos das competências processuais envolvidas na Filosofia para Crianças se estendem muito para além do tempo letivo que lhe é intencionalmente dedicado. A comunidade de investigação extrapola as paredes da sala de aula sempre que o mesmo tipo de diálogo compõe a base de pensamento noutras disciplinas. 
não deve dar a palavra aos amigos... assim não é justo! representações das crianças sobre o gestor da palavra na comunidade de investigação filosófica

Enquanto competência transversal, também o GP assume potencialidades pedagógicas que vão para além das sessões de $\mathrm{FpC}$, podendo tornar-se um recurso a adotar em qualquer outro momento do currículo. Tal como afirmam Ann Sharp e Laurance Splitter, "O que tem de ser compreendido é que as crianças são muito capazes de levar o pensamento e o diálogo que ocorre dentro da comunidade para as suas próprias vidas." (SPLITTER; SHARP, 1995, 182).

\section{referências}

BARDIN, Laurence. Análise de conteúdo. Lisboa: Edições 70, 1995.

BENJAMIN, Martin; ECHEVERRIA, Eugenio. Knowledge and the Classroom, In: SHARP, Ann Margaret; REED, Ronald (eds.). Studies in Philosophy for Children. Harry Stottlemeier's Discovery. Philadelphia: Temple University Press, p. 64-78, 1992.

BURGH, Gilbert. Seeking Justice as a Strategy for Teaching and Learning in SOSE: The Ring of Giges, The Veil of Ignorance and the Prisioner's Dillema". The Social Educator, Australia, v. 22, n. 3, p. 25-33, 2004.

BURGH, Gilbert; YORSHANSKY, Mor. Communities of inquiry: Politics, power and group dynamics. Educational Philosophy and Theory, Australia, v. 43, n. 5, p. 436-452, 2011.

COSTA-CARVALHO, Magda; MENDONÇA, Dina. Thinking like a community Reasonableness and Emotions. In: GREGORY, Maughn; HAYNES, Joanna; MURRIS, Karin (eds.). The Routledge International Handbook of Philosophy for Children. Abingdon: Routledge, p. 127-134, 2017.

DANIEL, Marie-France. Epistemological and Educacional Presuppositions of P4C: from Critical Dialogue to Dialogical Critical Thinking. In: Gifted Education International, USA, v. 22, n. 2 \& 3, p. 135-147, 2007.

ECHEVERRIA, Eugenio; HANNAM, Patricia. The community of philosophical inquiry (P4C). A pedagogical proposal for advancing democracy. In GREGORY, Maughn; HAYNES, Joanna; MURRIS, Karin (eds.). The Routledge International Handbook of Philosophy for Children, Abingdon: Routledge, p. 3-9, 2017.

FOUCAULT, Michel. Truth and power. In: RABINOW, Paul (ed.), The Foucault Reader, London: Penguin, p. 51-75, 1991.

HAYNES, Joanna. Children as Philosophers: Learning Through Enquiry and Dialogue in the Primary Classroom. London: Routledge, 2008.

KENNEDY, David. The Philosopher as Teacher. The role of a facilitator in a community of philosophical inquiry. In: Metaphilosophy, USA, v. 35, n. 4, p. 744-765, 2004.

LIPMAN, Mathew. Thinking in Education. Cambridge: Cambridge University Press, 2003.

LIPMAN, Mathew. Philosophy for Children's Debt to Dewey. In: TAYLOR, Michael; SCHREIER, Helmut; GHIRALDELLI Jr., Paulo (eds.) Pragmatism, Education and Children. International Philosophical Perspectives. Amsterdam/New York: Rodopi, p. 143-152, 2008.

LIPMAN, Mathew. The contributions of philosophy for deliberative democracy. In: Teaching Philosophy on the eve of the twenty-first century. International Federation of Philosophical Societies, Ankara, p. 6-29, 1998. 
LIPMAN, Mathew; MORIYÓN, Felix Garcia. Matthew Lipman: una Biografía Intelectual. Hacer: Revista Internacional de Filosofía Aplicada, Sevilha, n. 2, p. 177-200, 2011.

REED, Ronald; SHARP, Ann Margaret. Philosophie for Children: Pixie, Madrid: Ediciones de la Torre, 1998.

SASSEVILLE, Michel; GAGNON, Michel. Penser Ensemble à l'École, Québec: Les Presses de l'Université de Laval, 2007.

SHARP, Ann Margaret. Education of the Emotions in the Classroom Community of Inquiry. Gifted Education International, USA, v. 22, n. 2 \& 3, p. 248-257, 2007.

SHARP, Ann Margaret. The Community of Inquiry: education for democracy. Thinking. The Journal of Philosophy for Children, USA, v. 9, n. 2, p. 31-37, 1991.

SHARP, Ann Margaret. What is a 'Community of Inquiry'?. Journal of Moral Education, UK, v. 16, n. 1, p. 37-44, 1987.

SPLITTER, Laurance; SHARP, Ann Margaret. Teaching for better thinking. The classroom community of inquiry, Melbourne: Acer, 1995.

SPROD, Tim. Philosophical Discussion in Moral Education. The Community of Ethical quiry, London/New York: Routledge, 2001.

recebido em: 08.02.2017

aceito em: 30.03 .2017 